ла гиперреактивных тромбоцитов и состоянием стенки сосудов in vivo и in vitro. По-видимому, возникающие при СД нарушения углеводного и жирового обмена и их последствия (полиоловый путь метаболизма глюкозы, неферментное гликозилированние белков, активизация ПОЛ) затрагивают и тромбоциты, и эндотелий, однако степень изменения каждого из них зависит от местных условий в различных сосудистых бассейнах. Существуют определенные особенности гемодинамики в клубочках при СД. Можно предположить, что внутриклубочковая гипертензия как дополнительный фактор обусловливает реализацию активности подготовленных (гиперреактивных) тромбоцитов - агрегацию и высвобождение проагрегантов и вазоконстрикторов (серотонин, тромбоксан $\mathrm{A}_{2}$ и др.) и продуктов ПОЛ (МДА), которые, вызывая спазм сосудов и повреждения эндотелия, нарушают микроциркуляцию в клубочках, способствуют микротромбозу и формированию ДН.

\section{В ы в оды}

1. У крыс с хроническим аллоксановым диабетом в динамике его течения изменения функциональной и метаболической активности тромбоцитов наступают не одновременно: усиление образования МДА и снижение дезагрегации тромбоцитов отмечаются на 15-е сутки развития СД, тогда как увеличение АДФ-индуцированной агрегации и отсутствие изменений в содержании и продукции тромбоцитами МДА - на 60-е сутки течения СД.

2. На ранних этапах развития СД (15-е сутки) у крыс отмечается снижение АА аорты, прогрессирующее к 60-м суткам СД.

3. Выявлен параллелизм между появлением ранних признаков ДН, протеинурией и наличием пула гиперреактивных тромбоцитов, которым принадлежит определенная роль в механизмах повреждения сосудов клубочков на ранних этапах формирования диабетической ангиопатии.

\section{ЛИТЕРАТУРА}

1. Берулава М. Х. Морфологические изменения в почках при экспериментальном аллоксановом диабете. - Тбилиси. 1980.

2. Ефимов А. С. Диабетические ангиопатии. - М., 1989.

3. Задкова Г. Ю., Авакян Х. М., Марков А. М. // Пробл. эндокринол. - 1993. - № 5. - С. 40-43.

4. Корчин В. И., Ланкин В. 3. и др. // Бюл. экспер. биол. 1992. - № 9. - C. 279-282.

5. Сергиенко А. А. // Пробл. эндокринол. - 1991. - № 4. C. $24-26$

6. Шестакова М. В., Дедов И. И. // Тер. арх. - 1994. № 6. - C. $75-78$.

7. Befiore A. et al. // Vascular Complications in Diabetes Mellitus. - Basel, 1987

8. Noberasco G., Odetti P., Boeri D. et al. // Biomed. Pharmacother. - 1991. - Vol. 45, № 4-5. - P. 193-196.

9. Steffer M.W., Osterby R. et al. // Diabetes. - 1989. Vol. 38, № 9 - P. 1077-1083.

10. Stuart H. J., Murphy S., Oski F. A. // N. Engl. J. Med. 1975. - Vol. 292. - P. 10-13.

11. Stuart H. J. // Thromb. Haemost. - 1979. - Vol. 42. P. 649-654

12. Ts'ao C., Krajewski D., Galuzzo T. // Proc. Soc. exp. Biol. 1981. - Vol. 166. - P. 383-388.

13. Vane J. R., Bunting S., Moncada S. // Int. Rev. exp. Pathol. 1982. - Vol. 23. - P. 162-196.

14. Winocour P. // Diabetes. - 1992. - Vol. 41, Suppl. 2. P. $26-31$

Поступила 04.08.95

S.A. Shestakova, M.L. Stepanyan, V.A. Titova, N.V. Boikova FUNCTIONAL ACTIVITY OF PLATELETS IN THE EARLY PERIODS OF ANGIOPATHY FORMATION IN RATS WITH ALLOXANE DIABETES

$\mathrm{Su} \mathrm{m} \mathrm{mary}$. Functional and metabolic activity of platelets and antiaggregation activity of aortic wall, as well as the specific features in the structure of renal glomeruli were studied in rats at the early stages of alloxan diabetes development. A decrease of platelet disaggregation, increase in the levels of malonic dialdehyde (MDA) in nonactivated platelets, and an expressed increase of MDA production by thrombin-activated platelets were observed in animals with 15-day diabetes mellitus. A depression of the antiaggregation activity of the aorta was observed at the same period. In the renal glomeruli, ultrastructure of the epithelium was changed (destruction of its fenestrae, vacuolization, and detachment from the basal membrane), and proliferation of the mesangial elements of a glomerulus observed. In later periods of diabetes mellitus $(60$ days) the maximal increase of platelet aggregation activity and a continuing decrease of their disaggregation were observed, which were not paralleled by a higher production of MDA in nonactivated and activated platelets. Decrease of antiaggregation activity of the aorta and changes in the renal glomeruli progressed by day 60 of the disease: degranulated platelets and aggregations thereof were found in the lumens of glomerular capillaries.

\title{
- ОБЗОРЫ
}

О А. В. ВОРОНЦОН, М. В. ШЕСТАКОВА, 1996

УДК 616.379-008.64-06:616.61]-092-08(048.8)

А. В. Воронцов, М. В. ІІІестакова

ДИАБЕТИЧЕСКАЯ НЕФРОПАТИЯ: ПАТОГЕНЕЗ И ЛЕЧЕНИЕ

Эндокринологический научный центр (дир. - акад. РАМН И. И. Дедов) РАМН, Москва

В настоящее время диабетическая нефропатия (ДН) является ведушей причиной инвалидизации и смертности больных сахарным диабетом (СД). Развиваясь у $40-45 \%$ больных как инсулинзависимым - ИЗСД (I тип), так и инсулиннезависимым - ИНСД (II тип) СД [35], это грозное осложнение приводит $\mathrm{K}$ развитию хронической почечной недостаточности, а в итоге - к гибели больных от уремии.
Впервые поражение почек при СД было описано Р. Kimmelstiel и C. Wilson в 1936 г. [42]. Клинически оно характеризуется следующими проявлениями: нарастающей протеинурией (при неизменном мочевом осадке), артериальной гипертензией, формированием нефротического синдрома (примерно у $30 \%$ больных) и прогрессирующим снижением фильтрационной функции почек. Коварство этого осложнения СД состоит в том, что оно развивается постепенно и долгое время остает- 
Стаднн развнтия ДН (по С. Mogensen [51])

\begin{tabular}{|c|c|c|}
\hline Стадия ДН & Клинико-лабораторная характеристика & Сроки развития \\
\hline Стадия гиперфункции & $\begin{array}{l}\text { Увеличение СКФ (> } 140 \text { мл/мин); увеличение почечного кровотока; } \\
\text { гипертрофия почек; нормоальбуминурия (<30 мг/сут) }\end{array}$ & Дебют СД \\
\hline $\begin{array}{l}\text { Стадия начальных струк- } \\
\text { турных изменений почек }\end{array}$ & $\begin{array}{l}\text { Утолщение БМ клубочков; экспансия мезангиума; сохранение высо- } \\
\text { кой СКФ; нормоальбуминурия (<30 мг/сут) }\end{array}$ & 2-5 лет от начала заболевания \\
\hline Стадия начинаюшейся ДН & $\begin{array}{l}\text { МАУ (30-300 мг/сут); СКФ повышена или в норме; нестойкое по- } \\
\text { вышение АД }\end{array}$ & 5-15 лет от начала заболевания \\
\hline Стадия выраженной ДН & $\begin{array}{l}\text { Протеинурия (более } 300 \text { мг/сут); СКФ умеренно снижена; артериаль- } \\
\text { ная гипертензия }\end{array}$ & $\begin{array}{l}10-25 \text { лет от начала заболева- } \\
\text { ния }\end{array}$ \\
\hline Стадия уремии & $\begin{array}{l}\text { Снижение СКФ (менее } 10 \text { мл/мин); артериальная гипертензия; сим- } \\
\text { птомы интоксикации }\end{array}$ & $\begin{array}{l}\text { Более } 20 \text { лет от начала диабета } \\
\text { или 5-7 лет от появления про- } \\
\text { теинурии }\end{array}$ \\
\hline
\end{tabular}

Пр и меч ан и е. СКФ - скорость клубочковой фильтрации; БМ - базальная мембрана.

ся незамеченным, так как на начальных стадиях не вызывает у больного ощущения дискомфорта. А на поздних стадиях, когда наличие ДН уже не вызывает сомнений, предотвратить дальнейшее ее прогрессирование крайне сложно, а зачастую и невозможно

\section{СТАДИИ РАЗВИТИ ДН}

В нашей стране в течение многих лет использовалась классификация ДН В. Р. Клячко, в соответствии с которой выделялись пренефротическая, нефротическая и нефросклеротиче ская стадии. По этой классификации ДН диагностируется только с момента, когда у больного появляется протеинурия регистрируемая обычными лабораторными методами, что свидетельствует о выраженности и необратимости патологических изменений в почках. Современная классификация, выделяющая стадии, при которых еще отсутствуют клинические проявления, а выявляются только функциональные нарушения, была предложена С. Mogensen в [983 г. [51] (см. таблицу). В соответствии с данной классификацией первые 3 стадии обычными клиническими методами не выявляются (доклиническая стадия ДН). Наиболее информативным маркером ранних стадий ДН является определение микроальбуминурии (МАУ), под которой подразумевается экскреция альбумина с мочой в количестве от 30 до 300 мг/сут [51]. Выявление МАУ у больного СД I типа означает, что вероятность развития у него клинической картины ДН в ближайшие 10 лет составляет $80 \%$.

\section{1. Патогенез ДН}

\section{1. Метаболические нарушения}

\subsection{1. Нарушения углеводного обмена}

В настоящее время доказана прямая зависимость темпов развития ДН от уровня нарушений углеводного обмена у больных ИЗСД [26]. Гипергликемия оказывает повреждаюшее действие на сосуды клубочков как прямо, так и через активацию некоторых биохимических процессов. Прямая глюкотоксичность связана, в частности, с тем, что высокие концентрации глюкозы способны оказывать непосредственное повреждаюшее действие на эндотелий сосудов. Известно, что эндотелиальные клетки являются инсулиннезависимыми [11], поэтому в условиях гипергликемии глюкоза беспрепятственно проникает в них, вызывая нарушение их функции в результате патологических метаболических сдвигов [47]. Известно, что высокие концентрации глюкозы нарушают экспрессию генов, ответственных за синтез протеогликанов в культуре эндотелиальных клеток [48].

Одним из важнейших механизмов патогенного действия высокой концентрации глюкозы является неферментное гликозилирование белков, т. е. не требуюшая присутствия специфических ферментов реакция между глюкозой и аминокислотными остатками структурных и циркулирующих белков. Накопление как обратимых, так и (особенно) конечных продуктов гликозилирования оказывает повреждающее действие на почечные структуры, способствует поддержанию гиперфильтрации $[62,63]$. Гликозилирование структурных белков мезангия и базальной мембраны (БМ) клубочков приводит в конечном итоге $\mathrm{K}$ нарушению синтеза их основных компонентов, снижению зарядо- и размероселективности БМ, нарушению ее инфраструктуры и утолщению; одновременно с нарушением структуры и функций БМ гипергликемия инициирует экспансию клеток мезангия [63].
В патогенезе нарушения функции инсулиннезависимых тканей большое значение имеет преврашение глюкозы по полиоловому пути в сорбитол под влиянием фермента альдозоредуктазы. Накопление избыточного количества сорбитола в клетках повышает осмотическое давление и вызывает клеточный отек, создавая условия для нарушения функции клеток и способствуя нарушению микроциркуляции [20]. Образование внутриклеточного сорбитола происходит преимушественно в клетках эндотелия сосудов, почечных клубочков, нервных волокон, хрусталика, а также в перицитах сетчатки.

\subsection{2. Гиперлипидемия}

Патогенетическая роль нарушений липидного обмена в прогрессировании поражения почек при СД стала обсуждаться только в последние годы. Известно, что как при ИЗСД, так и при ИНСД отмечается повышение содержания в крови общего холестерина, триглицеридов и особенно холестерина липопротеинов низкой (ЛПНП) и очень низкой плотности [3]. При этом гиперлипидемия при СД может быть связана с декомпенсацией СД, сопровождающейся нарушением активности липопротеинлипазы, а также может быть обусловлена первичными нарушениями липидного обмена.

В последнее время показано, что наряду с гипергликемией гиперлипидемия может играть роль самостоятельного патогенетического фактора, индуцируюшего развитие ДН [5]. Так по данным H. Mulec и соавт. [53], гиперхолестеринемия у больных ИЗСД является важным фактором риска, прогностически определяющим развитие у них ДН. Это подтверждается и тем, что достижение нормализации содержания холестернна в крови способно замедлить прогрессирование ДН [46], однако механизмы влияния гиперлипидемии на развитие ДН пока мало изучены. По мнению исследователей, гиперлипидемия приводит к повреждению эндотелиальных клеток клубочков и отложению липидов в мезангии, что приводит к его экспансии, избыточному образованию экстрацеллюлярного матрикса и в конечном итоге к гломерулосклерозу [55]. Ряд исследований, проведенных на лабораторных животных, пока зывает, что гиперлипидемия, вызванная гиперхолестериновой диетой или обусловленная генетически, способна индуцировать развитие гломерулосклероза, а ее коррекшия препаратами нормализующими липидный состав крови, замедляет или предотвращает эти изменения [29, 33].

H. Jin-Soo и coaвт. [38] в 1992 г. показали, что морфологически изменения в почках у животных с индуцированным СД характеризуются развитием фокально-сегментарного гломерулосклероза с расширением мезангия из-за отложения мембраноподобного материала, пролиферацией мезангиальных клеток, имеющих липидные включения, и большим количеством пенистых клеток, представляющих собой макрофаги, содержащие большое количество липидов.

Механизм проникновения липидов в почечную ткань изучен недостаточно, однако, по-видимому, оно связано с повышенной проницаемостью деформированной БМ клубочков у больных с ДН. Что же касается причин появления лилидных включений в почечной ткани у больных с еше не поврежденным клубочковым фильтром при отсутствии клинических признаков поражения почек и даже гиперлипидемии, то, повидимому, в основе этого сложного процесса лежит внутриклубочковая гипертензия [4]. Характерно, что в почках крыс с индуцированным диабетом появление липидных отложений прямо обусловлено внутриклубочковой гипертензией, причем даже при отсутствии гиперхолестеринемии [59].

Липиды, накапливаясь в почечных структурах, приводят к нарушению их функции, вызывают пролиферацию мезанги- 
альных клеток и избыточную продукцию ими внеклеточного матрикса, что приводит к развития гломерулосклероза. Гиперлипидемия нарушает и функцию БМ клубочков. Связываясь с гликозаминогликанами, липиды приводят к снижению зарядоселективности БМ. Эти и, по-видимому, другие не до кон山а еще изученные механизмы определяют влияние нарушений липидного обмена на развитие ДН.

\section{2. Гемодинамические нарушения}

Согласно современным представлениям, последователь ность формирования гемодинамических сдвигов при ДН характеризуется следующей периодичностью. Гипергликемия по-видимому, является пусковым фактором в развитии нару шений внутрипочечной гемодинамики [66], появляющихся внутриклубочковой гипертензией, гиперфильтрацией и гиперперфузией почек $[4,6,30,74,75]$, а на более поздних стадия ДН присоединяется и системная артериальная гипертензия которая в свою очередь ускоряет развитие склеротических изменений в почечной ткани [27].

В ряде исследований, посвященных патогенезу ДН, убеди тельно доказано, что в основе ее возникновения и прогрессирования лежит внутриклубочковая гипертензия. Так, в исследованиях на животных с индуцированным СД с использованием микропункционной техники было показано увеличение градиента внутриклубочкового давления на фоне гиперглике мии, а применение препаратов, снижающих повышенную внутриклубочковую гипертензию, предотвращало развитие диабетической гломерулопатии [80]. У больных СД о развитии внутриклубочковой гипертензии косвенно свидетельству ет повышение показателей клубочковой фильтрации, часто возникаюшее задолго до появления явных клинических признаков поражения почек [18]. В исследованиях М. В. Шестаковой и соавт. [4] показано, что внутриклубочковая гипертензия, оцениваемая на основании определения функшионального почечного резерва, развивается уже на самых ранних стадиях и способна индуцировать развитие и прогрессирование нефропатии независимо от степени метаболического контроля и выраженности артериальной гипертензии.

Ведущим патогенетическим фактором развития устойчивого повышения внутриклубочкового давления при СД многие авторы считают нарушение регуляции тонуса афферентных и эфферентных артериол клубочков. Установлено, что уже на ранних стадиях СД афферентная артериола расширяется и утрачивает способность к ауторегуляции тонуса, в то время как тонус эфферентной артериолы не изменяется [72]. Этот дисбаланс может усугубляться повышенной чувствительностью эфферентных артериол к воздействию катехоламинов и ангиотезина II [79]. Вследствие такого дисбаланса возникает повышение градиента гидростатического давления в капиллярах клубочков, что приводит к гиперперфузии и гиперфильтрации Помимо этого, имеются доказательства того, что немаловажную роль в развитии гиперфильтрации может играть также повышение уровня глюкозы, кетоновых тел, гормона роста, имеющих место у больных СД.

Таким образом, роль внутриклубочковой гипертензии в развитии ДН доказана. Однако конкретные механизмы структурных и функциональных нарушений слагаемых нефрона требуют дальнейшего изучения. По-видимому, внутриклубочковая гипертензия нарушает структуру и проницаемость БМ, в результате чего белки, липиды и другие компоненты плазмы проникают через нее и откладываются в мезангии, что влечет за собой его экспансию, гиперпродукцию матрикса, а затем и склероз, что в конечном итоге-приводит к развитию характерного для СД синдрома [75]. С другой стороны, высказываются предположения о том, что механическое раздражение структурных компонентов клубочка вследствие повышенного гидростатического давления способствует увеличению объема мезангиального матрикса и гиперпродукции мезангиальными, эндотелиальными и эпителиальными клетками вещества, по биохимическому составу близкого к субстанции БМ клубочков [37].

На более поздних стадиях развития ДН отмечается, как правило, присоединение системной артериальной гипертензии. При этом у больных СД I типа причиной повышения АД обычно является ДН, тогда как при СД II типа чаще имеет место эссенциальная гипертензия, появляющаяся еще до развития почечной патологии [59]. Гипертония, развивающаяся при ДН, является низкорениновой и объемозависимой, т. е. она развивается вследствие первичной задержки натрия и воды почками при нормальных или даже сниженных показателях активности ренин-ангиотензиновой системы [36]. Кроме того, в исследованиях P. Weidmann и соавт. [76] обнаружено резкое повышение чувствительности сосудов к катехоламинам и ангиотензину II у больных СД, что также способствует повышению системного АД.

Многочисленный исследования убедительно доказывают, что артериальная гипертензия является фактором, в значи тельной мере способствуюшим прогрессированию поражения почек. Показано, что существует положительная корреляция между уровнем АД, с одной стороны, и нарастанием протеинурии [27], скоростью снижения клубочковой фильтрации и выраженностью гломерулосклероза, с другой, а достижение стойкой нормализации АД приводит к снижению протеинурии и замедлению снижения скорости клубочковой фильтрации $[57,58]$. По-видимому, в условиях нарушения ауторегуляции тонуса артериол клубочков и расширения приносящих артериол при нормальном или чаще повышенном тонусе суженных выносящих артериол повышенное системное АД может прямо и негативно влиять на сосуды клубочка [34], увеличивая внутриклубочковую гипертензию и способствуя прогрессированию ДН

\section{3. Нарушения гемостаза}

Большое значение в патогенезе диабетических ангиопатий вообше и поражения почек в частности отводится нарушениям сыстемы гемостаза. Характерные для больных СД повышение уровней факторов коагуляции в плазме, изменения актив ности антикоагуляционной системы и снижение фибриноли тической активности, а также гиперактивность тромбоцитов свидетельствуют о наличии у них состояния гиперкоагуляции, что приводит $\mathrm{K}$ нарушению микроциркуляции и развитию сосудистых осложнений.

Многочисленные исследования, посвященные нарушению тромбоцитарного звена гемостаза при СД, свидетельствуют выраженной активации тромбоцитов как in vivo, так и in vitro, причем в ряде случаев даже при отсутствии ангиопатий, что позволяет предположить, что изменение функции тромбоци тов предшествует развитию сосудистых осложнений [9]. Однако гиперактивность тромбоцитов более выражена при наличии диабетических ангиопатий [45]. Маркерами повышенной функциональной активности тромбоцитов являются увеличение уровня тромбоцитарного фактора $4, \beta$-тромбоглобулина и синтеза тромбоксана А2, а также выраженность спонтанной и индуцированной агрегации тромбоцитов in vitro. В исследованиях M. O'Donnell и соавт. [24] показано, что у больных СД типа с альбуминурией и протеинурией отмечаются более высокие уровни $\beta$-тромбоглобулина и тромбочитарного фактора 4 по сравнению с больными, у которых отсутствовала повышенная экскреция белка с мочой, а Р. Craven и соавт. [21] показали повышение синтеза тромбоксана А2 при диабетическом поражении почек у крыс. Важными для понимания причин активации тромбоцитов при СД являются данные о том, что существует связь между нарушениями липидного обмена и изменениями тромбоцитарного звена гемостаза [73]. В данном исследовании показано, что у больных СД с альбуминурией имеется четкая корреляция между уровнем ЛПНП и холестерина, с одной стороны, и содержанием тромбоксана В2 (стойкого метаболита тромбоксана А2) и $\beta$-тромбоглобулина, с другой. Возможно, взаимодействие избыточного количества ЛПНП, особенно их окисленной формы, с мембраной тромбоцита приводит к его активации. В то же время при СД отмечено снижение продукции сосудистым эндотелием простациклина, что также приводит к гиперагрегации [1]. Более того, D. Betteridge и coaвт. [10] и Н. Onodera и соавт. [54] показали что чувствительность тромбоцитов к простациклину при Сд снижается. Однако механизм активации тромбоцитов при СД изучен пока недостаточно.

Для СД характерно также нарушение плазменного звена гемостаза и гемостатических функций сосудистого эндотелия Многие исследователи отмечают, в частности, повышение содержания в плазме крови фактора Виллебранда в комплексе с фактором VIII, который синтезируется эндотелием [12]. Интересным представляется исследование [67], в котором показано, что уровень фактора Виллебранда был повышен у больных СД с поражением почек, а также у больных, ДН у которых развилась в течение 3 лет после обследования. При СД также отмечается изменение содержания в плазме и других факторов коагуляции. При этом активация внутреннего пути свертывания может быть вызвана стимуляцией тромбочитами факторов свертывания, а тканевый тромбопластин из поврежденной сосудистой стенки может вызывать гиперкоагуляцию через внешний путь. В частности, уже давно известно повышение при СД факторов V, IX и XII [25], VII [16]. Эти изменения сочетаются со снижением в крови больных СД активности одного из важнейших регуляторов гемостаза - антитромбина III, непосредственно индуцируемым гипергликемией [17], что 
также ведет к гиперкоагуляции и нарушению микроциркуляции.

\section{4. Нарушение функиии БМ клубочков и эндотелиальных клеток}

В последние годы все большее внимание исследователей привлекает значение измененного состояния эндотфлия почечных сосудов в развитии ДН. Эндотелий клубочковых капилляров является первым слоем клеток на пути ультрафильт рации, что определяет исключительную важность его состояния; он постоянно подвергается действию разнообразных ге модинамических и метаболических факторов, таких как нарушения углеводного и липидного обмена, системная и клубочковая гипертензия. Эндотелий чрезвычайно чувствителен к гипергликемии, так как эндотелиальные клетки являются инсулиннезависимыми и глюкоза беспрепятственно проникае в них, вызывая патологические биохимические реакции [11] Bсе эти факторы вызывают нарушение функции эндотелия что способствует развитию нефропатии. Это особенно важно, так как в последнее время стало ясно, что эндотелиальные клетки играют огромную роль в регуляции сосудистого тонуса. Благодаря ряду исследований были получены данные о том что эндотелий является источником биосинтеза тканевого ангиотензина II [4I], а также простациклина и брадикинина [49 771. Кроме того, в эндотелиальных клетках продуцируются еще более мощные регуляторы сосудистого тонуса - вазоконстриктор эндотелин-I [78], чувствительность почечных сосудов к которому в 10 раз выше, чем сосудов других органов [19], и эндотелиальный фактор релаксации (свободнорадикальная форма оксида азота [56]), уравновешиваюшие действие друг друга у здоровых людей. Однако при СД нормальное соотношение между веществами, оказывающими сосудосуживающее и сосудорасширяющее действие, нарушается. Так, в исследованиях F. Mattar и соавт. [50] продемонстрировано увеличение активности синтеза эндотелиального фактора релаксации у крыс с индуцированным диабетом, что приводит к сниженико тонуса приносящих артериол и повышению скорости клу бочковой фильтрации и внутриклубочкового гидростатического давления. Эти результаты были подтверждены и в клинических исследованиях: показано увеличение синтеза эндотелиального фактора релаксашии у больных СД I типа с ДН, причем максимальная активность отмечалась у больных с гиперфильтрацией [64]. В то же время продемонстрировано увеличение уровня эндотелина-I в плазме больных ИЗСД с микроальбинурией [69], а A. King и соавт. [43] показали, что избыток эндотелина приводит к спазму артерий клубочков, преимущественно эфферентных, что вызывает повышение внутриклубочкового гидростатического давления, но не сопровождается повышением клубочковой фнльтрации, так как одновременно снижается коэффициент ультрафильтрации (из-за сокрашения мезангиальных клеток). Кроме того, как уже было указано, эндотелий вырабатывает фактор Виллебранда, а также тканевый активатор плазминогена и его ингибитор [7]. $\mathrm{Ha-}$ рушение синтеза указанных биологически активных веществ, а также гиперпродукция эндотелием различных факторов роста [14] слособствуют прогрессированию ДН. В эксперименте с культурой ткани эндотелиальных клеток показано, что в условиях гипергликемии они продуцируют избыточное количество гликопротеинов, входящих в состав БМ, что приводит к ее утолщению [15]. В норме в состав БМ входят коллаген (преимушественно IV и V типа) и гликозаминогликаны: гепарансульфат, дерматансульфат, хондронтинсульфат, а также фибронектин. Гепарансульфат - отрицательно заряженный благодаря наличию сульфогруппы гликозаминогликан, представляющий собой боковую цепь гепарансульфатпротеогликана главного протеогликана БМ [40], играющего важнейшую роль в поддержании зарядоселективности стенки почечных капилляров по отношению к отрицательно заряженным белкам плазмы, прежде всего к альбумину. Кроме этого, гепарансульфат принимает участие в регуляции пролиферации мезангиальных клеток и образования внеклеточного матрикса [22]. При СД отмечается резкое снижение содержания гепарансульфата в БМ клубочка, в результате чего мембрана утрачивает свои зарядоселективные свойства и становится проницаемой для отрицательно заряженных молекул, что проявляется появлением и нарастанием альбуминурии. Этот факт установлен и подтвержден многочисленными исследованиями как на животных, так и на больных СД $[13,65]$, однако пока не вполне ясна причина этого явления. T. Deckert [22] выдвинул гипотезу, в соответствии с которой снижение содержания гепарансульфатпротеогликана в БМ может быть вызвано генетически обусловленным дефектом фермента $\mathrm{N}$-деацетилазы, в результате которого под действием гипергликемии происходит резкое снижение его активности и как следствие снижение про- дукции гепарансульфата. Это приводит к альбуминурии, расширению мезангия, избыточному образованию внеклеточного матрикса. Мезангиальные клетки также чувствительны к гипергликемии. Как показали Ј. Кгеisberg и соавт. [44] в экспе рименте с культурой мезангиальных клеток, будучи выраше ны в условиях повышенной концентрации глюкозы, они аккумулируют повышенное количество белков внеклеточного матрикса: коллагена IV, ламинина, фибронектина. Такая же закономерность, по-видимому, имеет место и в организме больных СД, что также способствует развитию гломерулосклероза.

\section{2. Современная тактика лечения и профилактики ДН}

СД в последние годы становится все более распространенным заболеванием. По данным экспертов ВО3, сегодня в мире насчитывается более 100 млн больных СД I и II типа и примерно столько же, если не больше, находятся на стадии предцабета или нарушенной толерантности к глюкозе. ДН, являющаяся сегодня одной из основных причин инвалидизации и смертности больных СД, становится все более серьезной социально-экономической проблемой, что определяет исключительную важность фундаментальных и прикладных исследований, целью которых является разработка эффективных методов и средств ранней (на доклинической стадии) диагностики, профилактики развития, а также лечения этого грозного осложнения СД. Поэтому в современной диабетологии основным принципом борьбы с ДН является превентивная тактика. Это означает, что лечение должно быть начато как можно раньше, задолго до развития необратимых изменений в почечной ткани. Разумеется, апробированы методы и средства лечения, которые и на клинической стадии позволяют несколько замедлить прогрессирование поражения почек, однако, к сожалению, они носят только паллиативный характер Учитывая основные механизмы развития ДН, комплексная терапия должна включать в себя коррекцию метаболических нарушений с помощью интенсивной инсулинотерапии [2], а также нормализащию системной и внутрипочечной гемодинамики и восстановление нарушенных функций внутрипочечных структур.

В последнее время все большее внимание исследователей уделяется поиску эффективных средств медикаментозной коррекции гемодинамических нарушений, имеющих место больного СД и играющих важную роль в патогенезе ДН. Из таких средств наибольший интерес вызывают ингибиторы ангиотензинпревращающего фермента - АПФ (каптоприл, эналаприл, рамиприл, лизиноприл и др.). В ряде работ показано, что препараты этой группы благоприятно влияют на состояние почек у больных СД. В частности, установлено, что на фоне их применения отмечается снижение микроальбуминурии и протеинурии $[6,68]$, а такое замедление снижения скорости клубочковой фильтрации на поздних сталиях ДН [58] причем М. В. Шестаковой и соавт. [6] было показано, что применение ингибитора АПФ эналаприла эффективно при лечении больных с протеинурией или микроальбуминурией, а также для профилактики развития ДН у больных с нормоальбуминурией и истощенным функциональным почечным резервом.

Эффективность ингибиторов АПФ при ДН может быть объяснена несколькими механизмами. Прежде всего, как в клинических [6], так и в экспериментальных [80] исследованиях была продемонстрирована способность препаратов этой группы устранять внутриклубочковую гипертензию, которая является основным патогенетическим фактором в развитии ДН. С друтой стороны, ингибиторы АПФ дают мощный гипотензивный эффект, что несомненно, усиливает нефропротективное действие этих препаратов [60] В то же время ингиби торы АПФ обладают преимуществом перед другими препаратами, снижающими системнос АД, так как в отличие от многих из них не оказывают нежелательнос действие на углеводный и липидный обмен [6].

Кроме того, имеются данные, свидетельствующие о том, что ингибиторы АПФ могут непосредственно влиять на селективную проницаемость БМ [52], а также предотвращать потерю клубочками геларансульфата [61]. И хотя не все исследователи разделяют мнение о положительном влиянии ингибиторов АПФ на состояние почек у больных СД и их преимуществе перед другими гипотензивными препаратами, их использование представляется очень перспективным.

Наряду с ингибиторами АПФ в последние годы в качестве перспективного направления патогенетической терапии ДН обсуждается применение препаратов, препятствуюших пролиферации мезангиальных клеток, а именно гепарина и его аналогов. Помимо выраженного влияния на систему гемостаза, гепарин обладает целым рядом других свойств. Недавно обнаружено, что он препятствует пролиферации мезангия н гиперпродукции им внеклеточного матрикса, т. с. предотвращает 
процессы, приводящие к развитию гломерулосклероза. Пря мые доказательства этого были получены в исследованиях как in vivo [28], так и in vitro [8]. В некоторых работах было также показано, что применение гепарина у больных СД с ДН вызы вает снижение альбуминурии [39]. Однако выраженное дейст вие гепарина на систему гемостаза ограничивает его широкое применение. В связи с этим особый интерес представляет исследование возможности применения других преларатов, со держащих гликозаминогликаны, оказывающие менее выраженное действие на системный гемостаз, но дающих такой же как и гепарин, антипролиферативный зффект [71]. Многочисленные экспериментальные исследования подтверждают положительное влияние гликозаминогликанов на состояние почек при СД. Так, показано, что назначение гликозаминогликанов при индуцированном СД предотвращает развитие морфологических изменений, характерных для ДН, и появление альбуминурии [31]. Эти препараты при уже развившейся нефропатии не только предотвращают ее прогрессирование, но н, возможно, даже вызывают обратное развитие почечных нарушений $[23,32]$. При этом в исследованиях J. Diamond и coaвт [23] было показано, что этот эффект гликозаминогликанов не зависит от их влияния на систему свертывания крови. Представляет большой интерес работа G. Gambaro и coaвт. [32], которой применение модифицированного быстродвижущегося гепарина с мол. массой 10400 Д у крыс с момента развития индуцированного СД предотврашало утолшение БМ клубочков, потерю ею отрицательных зарядов, а также нарушение проницаемости и зарядоселективности БМ клубочков; у этих животных сохранялась нормоальбуминурия. Более того, на значение данного препарата крысам с уже развившейся ДН вызывало обратное развитие морфологических изменений. Антипролиферативное действие гликозаминогликанов было показано in vivo: инъекции гликозаминогликанов крысам с индуцированным СД предотвращали пролиферацию мезангиаль ных клеток и экспансию мезангия [70]. При этом большое значение придается не только антимитогенному эффекту гликозаминогликанов, но и их способности предотвращать избыточную продукцию экстрацеллюлярного матрикса [28]. G Gambaro и соавт. [32] считают, что именно благодаря коррекции нарушенного синтеза клетками клубочка компонентов матрикса и БМ клубочков гликозаминогликаны предотвращают утолщение БМ и развитие гломерулосклероза.

Механизмы, благодаря которым реализуются описанные выше эффекты препаратов, содержащих гликозаминогликаны, не вполне ясны. В этом отношении представляют интерес данные о том, что гепарин и другие гликозаминогликаны регулируют активность некоторых факторов роста. J. Floege и соавт. [28] показали, что эти препараты способны снижать активность основного фактора роста фибробластов и тромбоцитарного фактора роста, которые при пролиферативном нефрите вызывают пролиферацию мезангия и гиперпродукцию экстрацеллюлярного матрикса.

Итак, следует подчеркнуть, что главное направление в решении проблемы ДН - это поиск методов и средств предупреждения развития ДН или применение комплексной терапии на самой ранней фазе ее развития. Такая терапия должна включать средства, направленные на нормализацию как внутриклубочковой гемодинамики, так и структуры и функций основных слагаемых стенки капилляра нефрона: эндотелия и БМ, а также мезангия.

\section{ЛИТЕРАТ УРА}

ட. Балуда В. П., Балаболкин М. И. // Пробл, эндокринол 1986. - № 2. - C. 32-35.

2. Дедов И. И. // Клин. фармакол. и тер. - 1993. - № 3. С. $16-20$.

3. Шагаева М. М., Собенин И. А., Славина Л. С. // Пробл, эндокринол. - 1993. - № 6. - С. $11-17$

4. ПІестакова М. В., Неверов Н. И., Дедов И. И. // Тер. арх. - 1993. - № 6. - C. 61-65.

5. Шестакова М. В., Дедов И. Н., Неверов Н. И. // Пробл. эндокринол. - 1993. - № 5. - С. 7-11

6. Шестакова М. В., Дедов И. И., Шереметьева О. В. Клин фармакол. и тер. - 1993. - № 3. - C. 22-26

7. Anwerx J., Bouillon R., Collen D. // Arteriosclerosis. - 1988. - Vol. 8. - P. 68-72

8. Ayo S. H., Kreisberg J. I. // J. Amer. Soc. Nephrol. - 1991. Vol. 2. - P. 1153-1157

9. Banga J. D., Sixman J. J. // Clin. Haematol. - 1986. Vol. 15. - P. 465-492

10. Betteridge D. J., Reckless J. P. D., Williams K. I. // Europ. J. clin. Invest. - 1982. - Vol. 12. - P. 395-398.

11. Betz A. L., Bowman P. D., Goldstein G. W. // Exp. Eye Res. 1983. - Vol. 36. - P. 269-277
12. Bloom A. L. // Clin. Haematol. - 1979. - Vol. 8. - P. 5376

13. van den Born J. // Diabetologia. - 1995. - Vol. 38. P. $161-172$

14. Brownlee M., Cerami A., Vlassara H. // N. Engl. J. Med. 1988. - Vol. 318. - P. 1315-1321.

15. Cagliero E., Maiello M., Boeri D // J. clin. Invest. - 1988 . Vol. 82. - P. 735-738.

16. Ceriello A., Giugliano D., Quatraro A. // Diabetologia. - 1988 - Vol. 31. - P. 889-891.

17. Ceriello A., Giugliano D., Quatraro A. // Ibid. - 1990 . Vol. 33 - P. 163-167.

18. Christiansen J. S. // Dan. med. Bull. - 1984. - Vol. 31. P. 349-361

19. Clozel M., Clozel J.-P. // J. Pharmacol. exp. Ther. - 1989. Vol. 250 - P. 1125-1131.

20. Cogan D. // Ann. intern. Med. - 1984.- Vol. 101. - P. 8291

21. Craven P. A., Melhem M. F., DeRubertis $F . R$. // Kidney int. 1992. - Vol. 42. - P. 937-946.

22. Deckert T., Horowitz I. M., Kofoed-Enevoldsen A. // Diabetes. - 1991 - Vol. 40. - P. 764-770.

23. Diamond J. R., Karnovsky M. J. // Renal. Physiol. Biochem - 1986. - Vol. 9. - P. 366-374.

24. O'Donnell M. J., Le-Guen C. A., Lawson N. // Diabet. Med. - 1991. - Vol. 8. - P. 624-628

25. Egebert O. // J. clin. Lab. - 1963. - Vol. 15. - P. $833-$ 838 .

26. Feldt-Rasmussen B., Mathiesen E., Deckert T. // Lancet. 1986. - Vol. 2. - P. 1300-1304

27. Feldt-Rasmussen B., Norgaard $R$., Jensen $T$. // Acta diabetol. lat. - 1990. - Vol. 27. - P. 173-179.

28. Floege J., Eng E., Young B. A. // Kidney int. - 1993. Vol. 34. - P. 638-641.

29. French $S$. $W$., Yamanaka $W$., Ostward R. // Arch. Pathol 1967. - Vol. 83. - P. 204-2í0.

30. Fujihara C., Padilha R., Zaiz R. // Diabetes. - 1992. Vol 41. - P. 286-293.

31. Gambaro G., Cavazzana A. O., Luzi P. // Kidney int. - 1992 - Vol. 25. - P. 376-382.

32. Gambaro G., Venturini A. P., Noonan D. M. // Ibid. - 1994 - Vol. 46. - P. 797-806.

33. Harris K. P. G., Purkerson M. L., Yates J. // Amer. J. Kidney Dis. - 1990. - Vol. 15. - P. 16-23

34. Hashimoto Y., Ideura I., Yoshimura A. // Diabetes. - 1989. Vol. 38. - P. 1109-1113

35. Hasslaher Ch., Ritz E., Wahl P. // Nephrol. Dial. Transplant - 1989 - Vol 4 - P. 859-863.

36. Hommel E., Mathiesen E. R., Giese J. // Scand. J. clin. Lab Invest. - 1989. - Vol. 49. - P. 537-544

37. Hostetter T. H., Rennke H. G., Brenner B. M. // Amer. J. Med - 1982. - Vol. 72. - P. 375-380

38. Jin-Soo H., Yoshinori S., Kunio D. // Int. J. exp. Pathol. 1992. - Vol. 73. - P. 75-84.

39. Kaizu K., Uriu K., Hashimoto O. // Nippon Jin. Gakkai Shi. 1993. - Vol. 35. - P. 35-42.

40. Kanwar Y. S., Lin Z. Z., Kashihara N. // Semin. Nephrol. 1991 - Vol 11 - P. 390-413.

41. Kifor I., Dzau V. J. // Circ. Res. - 1987. - Vol. 60. P. $422-426$.

42. Kimmelstiel P., Wilson C. // Amer. J, Pathol. - 1936. Vol. 12. - P. 83-97.

43. King A. J., Brenner B. M., Anderson S. // Amer. J. Physiol. 1989 - Vol 256 - P. F1051-F1058

44. Kreisberg J. I., Ayo S. H. // Kidney int. - 1993. - Vol. 43. P. $109-113$

45. Kubo A. // J. Jap. Diabet. Soc. - 1988. - Vol. 31. - P. $155-$ 161

46. Lam K. S. L., Chang I. K. R., Janus E. D. // Diabetologia. 1995. - Vol. 38. - P. 604-609.

47. Lorenzi M. // Diabet. Metab. Rev. - 1992. - Vol. 8. P. 85-103.

48. Lorenzi M., Montisano D., Toledo S. // J. clin. Invest. - 1986 - Vol. 77. - P. 322-325

49. Mac Intyre T. M., Zimmerman G. A., Satoh K. // Ibid. - 1985. - Vol. 76. - P. 27I-280

50. Mattar F. L., Padilha R. M., Zatz R. // International Congress of Nephrology, 12-th. - Jerusalem, 1994. - P. 421.

51. Mogensen C., Christensen C., Vittinghus E. // Diabetes. 1983 - Vol 32 - P. 64-78

52. Morelli E., Loon N., Meyer T. // Ibid. - 1990. - Vol. 39. P. $2-8$.

53. Mulec H., Johnson S.-A., Bjorck S. // Lancet. - 1990. Vol. 335. - P. 1537-1538 
54. Onodera H., Hirata T., Sugaware H. // Tohoku J. exp. Med. 1982. - Vol. 137. - P. 423-428.

55. Oshsava H., Yamabe H., Ozawa K. // Nephron. - 1988. Vol. 50. - P. 66-75.

56. Palmer R. M. J., Ferrige A. G., Moncada S. // Nature. - 1987 - Vol. 327. - P. 524-526

57. Parving $H .-H$., Andersen A. R., Smidt U. M. // Brit. med. J. 1987. - Vol. 294. - P. 1443-I447.

58. Parving H.-H., Hommel E., Nielsen M. D. // lbid. - 1989. Vol. 299. - P. 533-536.

59. Parving H. $H$. // International Textbook of Diabetes Mellitus / Eds K. G. Alberti et al. New York, 1992. - Vol. 2. P. $1521-1534$.

60. Passa P., Leblane H., Marre M. // Diabet. Care. - 1987 . Vol. 10. - P. 200-204.

61. Reddi A. S., Ramamurthi R., Miller M.// Biochem. Med. Metab. Biol - 1991. - Vol. 45. - P. 119-131.

62. Sabbatini M., Sansone G., Uccello F. // Kidney int. - 1992. Vol. 42. - P. 875-881.

63. Sensi N., Tanzi P., Bruno M. // Nephron. - 1989. - Vol. 52. - P. 222-226.

64. Shestakova M., Ragosin A., Dedov I. // Diabetologia. - 1994 - Vol. 37. - P. A-190.

65. Shimomura H., Spiro R. G. // Diabetes. - 1987-Vol. 36. P. 374-381.

66. Stackhouse S., Miller P., Park S., Meyer T. // Ibid. - 1990 . Vol. 39. - P. 989-995.

67. Stehouwer C. D., Stroes E. S., Hackeng W. H. // Ibid. - 1991. - Vol. 40. - P. 971-976.
68. Taguma Y., Kitamoto Y., Futaki G. // N. Engl. J. Med. 1985. - Vol. 313. - P. 1617-1620.

69. Takahashi K., Ghatei M., Lam H.-C. // Diabetologia. - 1990. - Vol. 33. - P. 306-310.

70. Tang W. W., Wilson C. B. // J. Amer. Soc. Nephrol. - 1992. - Vol. 3. - P. 921-929.

71. Tiozzo R., Cingi M. R., Reggiani D. // Thromb. Res. - 1993. - Vol. 70. - P. 99-106.

72. Tooke J. E., Shore A. C. // Textbook of Diabetes / Eds J Pickup, G. Williams. Boston, 1991. - Vol. 2. - P. 546-553.

73. Toth L., Szenasi P., Varsanyi N. M., Szilvasi I. // Orv. Hetil. 1992. - Vol. 133. - P. 1037-1040.

74. Viberti $G$. C. // Current Therapy in Nephrology and Hypertension / Ed. R. Glassock. - Toronto, 1987. - P. 109-113.

75. Viberti G. C., Walker J. D., Pinto J. // International Textbook of Diabetes Mellitus / Eds K. G. Alberti et al. New York, 1992. - Vol. 2. - P. 1267-1328.

76. Weidmann P., Beretta-Piccoli C., Trost B. // Hypertension. 1985. - Vol. 7, Suppl. 2. - P. 33-42.

77. Wiemer G., Schlkens B. A., Becker R. H. A. // Ibid. - 1991. Vol. 18. - P. 558-563.

78. Yanagisava M., Kurihara H., Kimura S. // Nature. - 1988. Vol. 322. - P. $411-415$.

79. Yuan B. N., Robinetfe J. B., Gonger J. D. // Amer. J. Physiol. - 1990. - Vol. 258. - P. F741-F750.

80. Zatz R., Dunn B. R., Meyer T. W. // J. clin. Invest. - 1986. Vol. 77. - P. 1925-1930

Поступила 07.09.95

(C). KROTKIEWSKI, 1996

УДК 616.74-005-092:616-008.9

M. Krotkiewski

КАПИЛЛЯРИЗАЦИЯ МЫШЦ, ИХ МОРФОЛОГИЯ И ПАТОГЕНЕЗ МЕТАБОЛИЧЕСКОГО СИНДРОМА

Департамент медицинской реабилитации Гетеборгского университета Сахлгринского госпиталя, Швеция

Морфологические изменения в мышцах, связанные с уменьшением количества быстрых, окислительных мышечных волокон IIA типа и увеличением количества быстрых, гликолитических мышечных волокон ІІБ типа, а также нарушение кровоснабжения мышечной ткани, рассматривались нами при многих патологических состояниях, связанных с инсулиновой резистентностью.

Нарушение тканевого кровоснабжения, тесно связанного с уменышением чувствительности к инсулину и степенью гипертензии, наступает на сравнительно раннем этапе, в то время как увеличение количества мышечных волокон типа ІІБ пронсходит позже и связано с повышением концентрации атерогенных факторов и гиперлипемией.

Мышечные волокна (МВ) типа ІІБ - наиболее нечувствительный к инсулину тип МВ и не адоптирован к окислению жира во время мышечной работы. Это способствует дальнейшему развитию инсулиновой резистентности и ожирению; при этом избыток жирных кислот направляется в печень, вторично нарушая ее функцию. Подавляет работу печени также избыточное количество инсулина. Гиперинсулинемия ведет к угнетению синтеза таких специфических протеинов, как белок, транспортирующий тестостерон (глобулин, связывающий половой гормон). В результате повышенная концентрация свободного тестостерона ведет к вирилизации женщин и дальнейшсму развитию инсулиновой нечувствительности

В отличие от существовавшей ранее концепции, отводившей основную роль интраабдоминальной жировой ткани, мышцы и печень должны рассматриваться также как органы, участвующие в патогенезе и развитии метаболического синдрома.

\section{Жировая ткань}

Взаимосвязь ожирения, гипертензии и диабета была обнаружена еше в 40-х годах, когда начали входить в употребление такие термины, как diabesity (diabetes + obesity), т. е. диабет и ожирение; obitension (obesity + hypertension), т. е. ожирение и гипертензия.

В это же время начинается изучение как потенциальной патогенетической роли жировой ткани, так и значения ее топографии [37]. Сейчас нам известна связь межлу ожирением и такими факторами метаболического риска, как гиперхоле- стеринемия, гипертриглицеридемия, гипергликемия, гиперинсулинемия, гипертензия и диабет [16]. Также мы знаем о связи между величиной избыточной массы и распределением жировой ткани [13].

Не так давно была установлена прогностическая роль распределения жировой ткани при инфаркте миокарда, инсульте, диабете и внезапной смерти $[27,28]$.

Инсулиновая резистентность жировой ткани главным образом связана с транспортом глюкозы. Более того, наступлению инсулиновой резистентности способствует ухудшение глюкозонакапливающей способности мышечной ткани [29]. А так как метаболизм глюкозы в жировой ткани играет количественно малую роль, то латогенетическая роль висцерального жира представляется лишь фактором, способствующим развитию инсулиновой резистентности в печени. Таким образом, патогенез метаболического синдрома может быть представлен как последовательность патогенетических изменений в жировой ткани, печени и мышцах (рнс. 1)

\section{Печень}

Перегрузка печени свободными жирными кислотами из висцеральной жировой ткани ведет к постепенному развитию в ней стеатоза. Нарушение некоторых других функций печени совпадает с уменьшением инсулинового клиренса и гипергликемией, способствующими, например, понижению концентрации глобулина, связывающего половой гормон. Низкая концентрация этого белка в свою очередь вызывает увеличение концентрации свободного тестостерона в плазме. Считается, что у тучных женшин [5] и женшин с синдромом поликистозных яичников [8] свободный тестостерон способствует развитию инсулиновой нечувствительности. Высокий уровень свободного тестостерона ведет К повышению активности печеночной триглицеридлипазы и низкой концентрации липопротендов высокой плотности (ЛПВП) в плазме [36]. Малая концентрация ЛПВП-холестерина - характерный признак абдоминального ожирения [4]. Интенсивное снабжение печени свободными жирными кислотами из висцеральной жировой и мышечной тканей ведет $\mathrm{k}$ гипертриглицеридемии и повышению уровня липопротеидов низкой плотности и общего холестерина, что также является типичными признаками абдоминального ожирения. 